Aporte Santiaguino. 10 (1), 2017: 75-86

ISSN 2070-836X

\title{
Desaceleración de la economía y el riesgo crediticio en la región Áncash, entre 2010 y 2015
}

Slowing economy and the credit risk in the Ancash region, between 2010 and 2015

Antonio Huamán Osorio ${ }^{1}$

\section{RESUMEN}

Evidencia la relación inversa entre la desaceleración de la economía y el riesgo crediticio en la región Áncash, entre 2010 y 2015. El tipo de investigación es aplicada, por su diseño es no experimental y de carácter cuantitativo. Se considera como población y muestra los datos estadísticos de serie temporal; Producción Bruta Interna regional (PBIr) indicador de desaceleración económica y la tasa de morosidad crediticia como riesgo crediticio. La información estadística se ha obtenido de los reportes estadísticos del Banco Central del Perú, sucursal Trujillo. En el procesamiento de los datos se ha empleado el programa SPSS 21. El resultado de investigación evidencia que la economía de la región Áncash creció en el 2010, en 18.2\%, para luego paulatinamente descender hasta $-9.9 \%$ en 2014, y luego recuperarse muy levemente en 2.6\% en 2015. Adicionalmente, en ese mismo período la colocación de créditos tanto a empresas como a familias se mantuvo en ascenso, a pesar de la desaceleración de la economía regional, es en ese momento cuando se iba incubando el riesgo crediticio para luego en el mediano plazo reflejarse en una mayor tasa de morosidad. Para conocer el grado de asociación entre las variables desaceleración económica y el riesgo crediticio, se ha empleado el coeficiente de correlación lineal de Pearson. El resultado de la estimación de Pearson es -0.83 , lo que confirma la existencia de un alto grado de asociación en dirección inversa entre desaceleración económica y riego crediticio. Se estima que a partir de 2015 las entidades financieras asentadas en la región Ancash, afronten problemas de falta de liquidez y rentabilidad.

Palabras clave: desaceleración económica; morosidad crediticia; entidades financieras.

1 Universidad Nacional Santiago Antúnez de Mayolo. Huaraz, Perú. 


\section{ABSTRACT}

Evidence the inverse relationship between the economic slowdown and credit risk in the Ancash region, between 2010 and 2015. The type of research is applied because of its non-experimental and quantitative nature. It is considered as population and shows the statistical data of temporal series; Regional Gross Domestic Production (GDP) indicator of economic slowdown and the rate of credit default as credit risk. The statistical information has been obtained from the statistical reports of the Central Bank of Peru, branch Trujillo. In the processing of the data the SPSS program 21 has been used.

The research results show that the economy of the Ancash region grew by $18.2 \%$ in 2010 , then gradually declined to $-9.9 \%$ in 2014 , and then recovered very slightly by $2.6 \%$ in 2015 . Additionally, Credit and corporate loans continued to rise, despite the deceleration of the regional economy, it was at that point that credit risk was incubated and then reflected in a Arrears

To know the degree of association between the economic deceleration and credit risk variables, the Pearson linear correlation coefficient was used. The result of the Pearson estimation is - 0.83 , which confirms the existence of a high degree of association in the reverse direction between economic deceleration and credit irrigation. It is estimated that from 2015 the financial institutions settled in the region Ancash, face problems of lack of liquidity and profitability.

Keywords: economic deceleration; loan delinquency; financial institutions.

\section{INTRODUCCIÓN}

El indicador principal de la desaceleración económica es el PBI regional, este indicador ha descendido de manera sostenida a partir de 2010, lo que ha impactado negativamente sobre las ventas e ingreso de las empresas y las familias; sin embargo, este hecho no ha mermado el optimismo de estos agentes económicos, quienes han mantenido la percepción de una pronta recuperación de la economía regional, muestra de ello es el comportamiento ascendente de la colocación de los créditos bancarios en el mismo período de la desaceleración económica. En este contexto de cierto optimismo, las entidades financieras ${ }^{2}$ subestimaron el riesgo crediticio, al relajar sus exigencias a los prestamistas.

Frente al hecho de desaceleración de la economía regional, se mantuvo el optimismo de los agentes económicos (empresas, familias y entidades financieras) por la recuperación de sus ingresos en el corto plazo, dado ese contexto; el

\footnotetext{
Las entidades financieras en la región Áncash están conformadas por la banca múltiple y por las micro financieras o entidades no bancarias agrupadas en Cajas Municipales de Ahorro y Crédito, Cajas Rurales, Edipymes, ONGs y Cooperativas.
} 
presente trabajo tiene como objetivo principal encontrar el grado de relación entre la desaceleración de la economía y el riesgo crediticio en la región Áncash, entre 2010 y 2015, si esta relación es estable, los agentes económicos deberán considerar dentro de sus políticas de endeudamiento.

La teoría keynesiana (1943) dice que en épocas de crecimiento económico el grado de optimismo suele aumentar entre los agentes económicos y se mantiene por cierto tiempo a pesar de la desaceleración económica, y se subestima el riesgo crediticio; es el caso de la región Áncash, donde el riesgo crediticio se mantuvo oculto al principio de la desaceleración económica regional, pero, en el mediano plazo terminó destapándose dicho riesgo en mayor morosidad crediticia, lo que condujo a las entidades financieras a elevar sus provisiones por créditos impagos.

$\mathrm{Al}$ respecto, Vera y Costa (2007) sostienen que el elevado optimismo, la euforia colectiva y una sobrevaloración de los colaterales (bienes raíces) generan un alto apalancamiento empresarial y personal que eleva la exposición de los deudores a los shocks económicos.

Delgado y Saurina (2004) muestran mediante resultados econométricos que existe una relación negativa entre la actividad económica y la tasa de morosidad, así, un cambio del $1 \%$ en la tasa de crecimiento del PBI tendría un impacto negativo de 1,02 puntos en la tasa de morosidad; es decir, una caída de la tasa de crecimiento del $2 \%$ al $1 \%$ se traduciría en un aumento a largo plazo del ratio de morosidad de 1.02 puntos porcentuales.

Siguiendo a Keynes (1943), se evidencia que los agentes económicos no son individuos totalmente racionales, sino que se dejan llevar por impulsos de confianza y desconfianza sobre el futuro. En la región Áncash, los agentes económicos han actuado con algún grado de irracionalidad al seguir endeudándose, sabiendo que la economía se encontraba en desaceleración con la caída sostenida del PBI regional y el empleo.

La desaceleración de la economía en la región Áncash se inicia a partir de año 2010 (BCRP, 2015). En ese año la economía regional creció en 18.2\%; pero en los sucesivos años el ritmo de crecimiento fue desacelerándose hasta caer en 2014 en $-9.9 \%$, para luego recuperarse muy levemente en $2.2 \%$ en 2015. Mientras que las colocaciones de crédito en la región en 2010, fue de 1 mil 749 millones de soles, luego de trascurridos cinco años llegó a alcanzar 3 mil 184 millones de nuevos soles, mostrando un crecimiento de $82 \%$, y el precio principalmente de las viviendas y terrenos seguían subiendo, entre los años 2010 y 2014, hasta que recién se detuvo en 2015. 


\section{MATERIALES Y MÉTODOS}

El tipo de trabajo es aplicado, puesto que con los resultados obtenidos se puede dar solución al problema de la creciente provisión para deudas impagas que enfrentan las entidades financieras. El diseño es no experimental cuantitativa. Para determinar el grado de asociatividad entre desaceleración económica y riesgo crediticio se ha empleado el coeficiente de correlación lineal de Pearson. La fuente de información es secundaria, se ha obtenido de los reportes estadísticos del Banco Central del Perú, sucursal Trujillo, dicha información ha sido procesada usando el programa SPSS 21.

\section{RESULTADOS}

Según las estadísticas presentadas por el Banco Central de Reserva del Perú (BCRP), en los últimos cinco años la economía peruana presenta una tendencia decreciente. El año 2010, el Producto Bruto Interno (PBI) creció por encima del $8 \%$, pero a partir de este año, es notoria la desaceleración de la economía, sin embargo, aún el desempeño muestra cifras positivas al haber alcanzado un crecimiento promedio de $6.5 \%$ entre 2010 y 2015 . El comportamiento de la inversión privada sigue la misma tendencia aunque con una mayor volatilidad, este hecho es notorio en el sector primario (minería), que ha sido el principal motor de la economía peruana, esta caída de la inversión privada obedece en gran parte a la contracción de la demanda de minerales en el mercado internacional; así mismo el consumo privado de manera progresiva se ha ajustado a la tendencia del PBI.

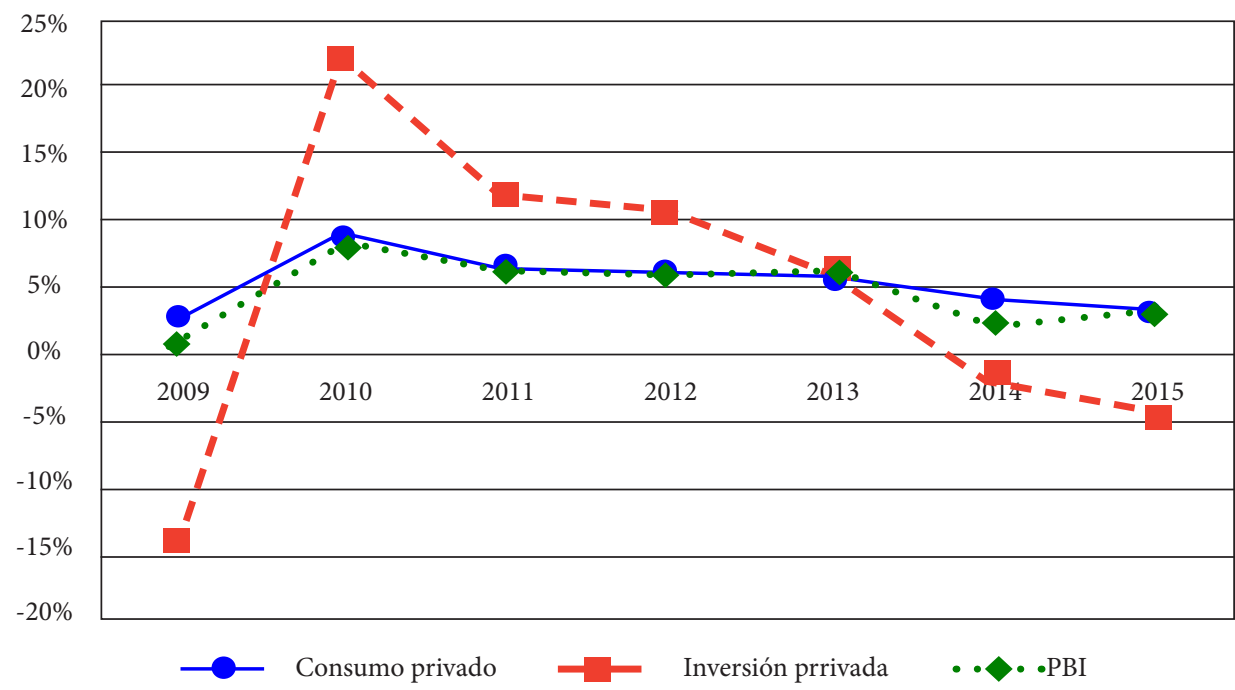

Figura 1. Evolución del PBI, inversión y consumo privado. Fuente: BCRP, estadísticas económicas (2015). 
La economía de la región Ancash, sigue casi la misma tendencia de desaceleración de la economía nacional, obviamente con ciertas particularidades. Precisamente para entender las propias características de la región Áncash, se ha revisado la estructura económica de esta región. Al revisar la contribución de los sectores productivos al PBI regional, resalta el sector primario, sobre todo la minería, que ha venido contribuyendo con más del $44 \%$ a la creación del PBI regional. Es evidente que el aporte de este sector tiene mayor peso respecto a las demás actividades productivas.

Siguen en importancia para la economía regional los sectores manufactura, construcción y el comercio que contribuyen con $8.3 \%, 7 \%$ y $6.7 \%$, respectivamente. Los cuatros sectores productivos mencionados acumulan un total de $66.3 \%$ de participación en la economía regional.

Los demás sectores como la agricultura, transportes, administración pública y pesca, tiene menor participación en la creación del PBI regional, pero, son importantes por ser intensivas en mano de obra, sobre todo el sector agricultura. Por ejemplo, la diferencia entre la actividad minera y la agricultura radica, en que el primero cuenta con tecnología moderna, por lo que es alta la productividad de sus trabajadores, mientras que en el segundo se sigue usando herramientas artesanales sobre todo en la zona sierra de la región, convirtiéndola en un sector de baja productividad, por esta razón la minería crea mayor valor agregado, por ende su contribución es mayor a la creación PBI regional.

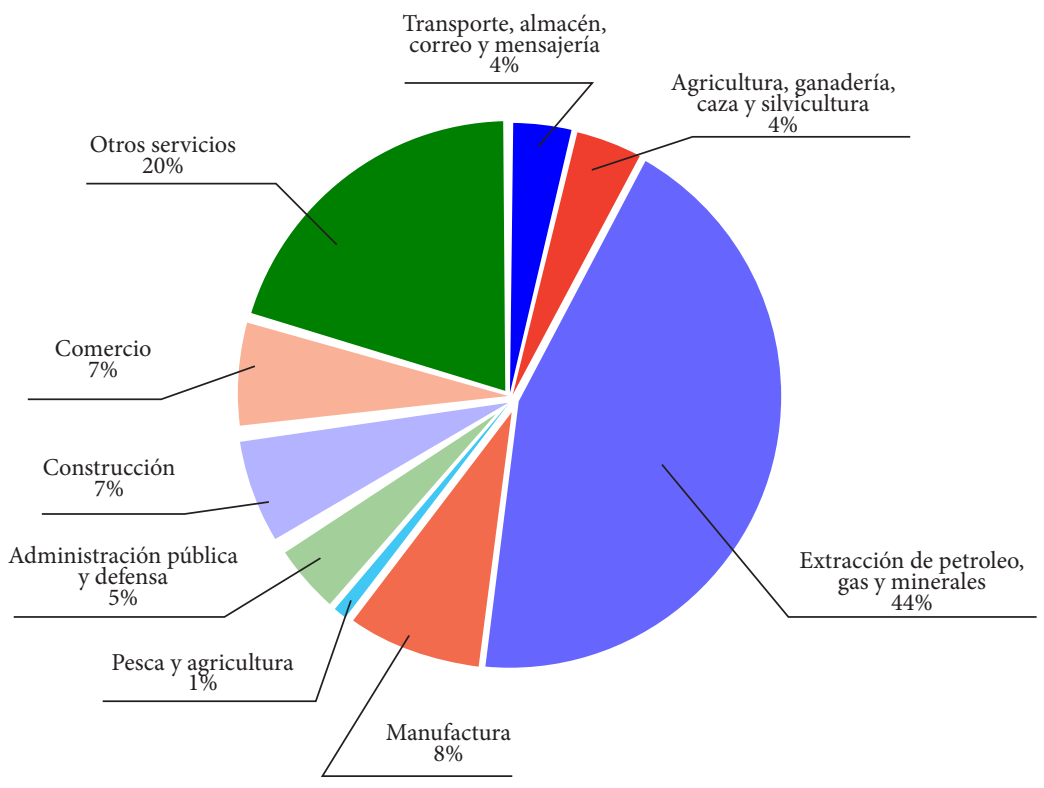

Figura 2: Estructura de la economía de Áncash (en \%), 2015.

Fuente: BCRP, sucursal Trujillo, estadísticas económicas (2015) 
La desaceleración de la economía en la región Áncash ha sido progresiva como efecto de la caída en la producción minera y construcción. Al igual que en el país, también en la región estos sectores productivos han sufrido un retroceso debido a shock externo, proveniente del mercado internacional de minerales donde se ha reducido la demanda de los principales metales como cobre, zinc, plata y oro, con la consecuente caída del precio internacional de minerales, lo que ha desincentivado a la inversión extranjera directa.

Gracias al boom minero, en Áncash, el promedio de crecimiento de la economía regional en los últimos 5 años ha sido superior al 6.5\%. En ese período pudo ubicarse por encima del promedio nacional. En la Figura 3, se muestra la evolución del PBI regional, que por cuatro años consecutivos presenta un crecimiento positivo, pero con una tendencia decreciente, hasta caer en $-9.9 \%$ en el año 2014; a partir de ahí ha mostrado una lenta recuperación, alcanzando una cifra positiva de $2.6 \%$ de crecimiento en el 2015; esta cifra es aún menor a la tasa de crecimiento de la economía nacional que fue de $3.2 \%$ en el mismo año.

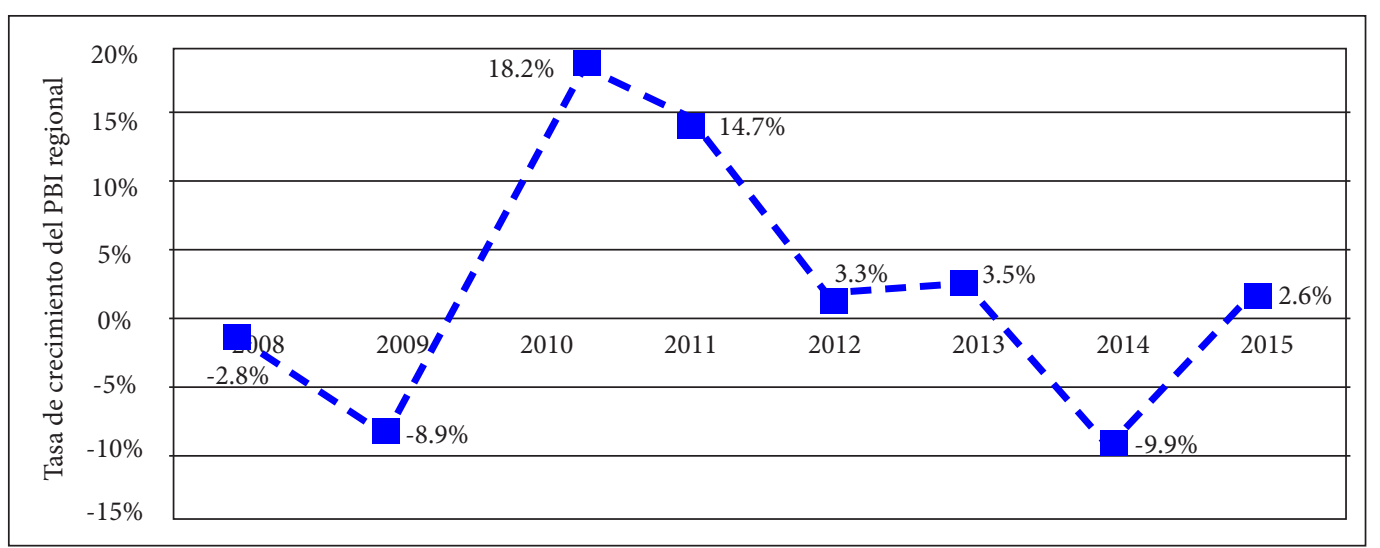

Figura 3: Desaceleración de la economía regional.

Fuente: BCRP, sucursal Trujillo, estadísticas económicas (2015)

El sistema financiero regional básicamente está organizado en dos grupos de empresas financieras; la banca múltiple ${ }^{3}$, y las entidades no bancarias ${ }^{4}$. Estas entidades son las encargadas de financiar vía créditos a empresas y familias.

En la estructura de créditos en la región Áncash, resalta la participación de la banca múltiple. El 78\% del total de crédito bancario es otorgado por estas entidades, seguidas por no bancarias (micro financieras), que han participado tan solo con el 15\% del total de créditos. La estructura crediticia se completa con

\footnotetext{
3 La banca múltiple está conformada por todos los bancos que operan en el mercado financiero peruano.

${ }^{4}$ Las entidades no bancarias están integradas por las Cajas Municipales, Cajas Rurales, Edipymes, ONGs y Cooperativas.
} 
la participación del Banco de la Nación y Agro Banco, cada uno ellos con 5\% y $2 \%$ de participación respectivamente.

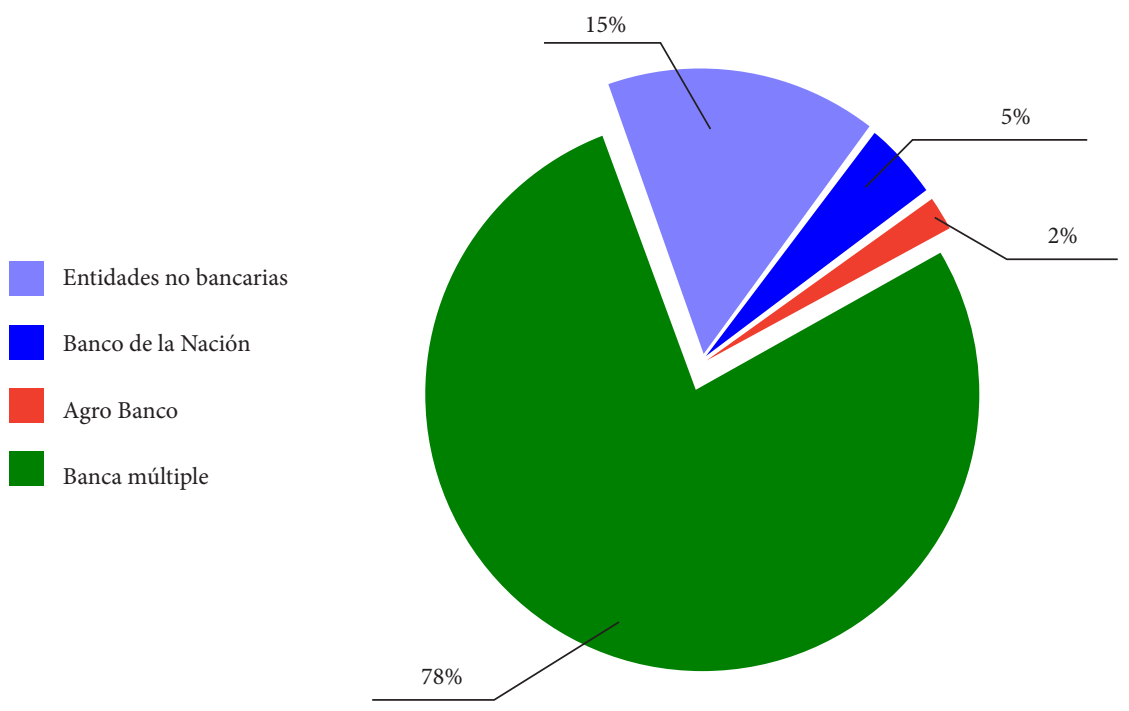

Figura 4: Crédito otorgado por el sistema financiero en Áncash, 2015.

Fuente: BCRP, sucursal Trujillo, estadísticas económicas (2015)

El comportamiento de las colocaciones de crédito es creciente, significa que tanto las empresas como las familias se van endeudando cada vez más, con la perspectiva que sus ingresos van mejorar en el corto plazo a pesar de la tendencia decreciente del PBI regional.

Tabla 1. Crédito en el sistema financiero en Áncash (saldo en millones de soles)

\begin{tabular}{ccccccc}
\hline & \multicolumn{6}{c}{ Años } \\
\cline { 2 - 7 } Entidades crediticias & 2010 & 2011 & 2012 & 2013 & 2014 & 2015 \\
\hline Banco de la nación & 84 & 89 & 95 & 113 & 132 & 154 \\
Agro banco & 0 & 0 & 0 & 25 & 50 & 59 \\
$\begin{array}{c}\text { Banca múltiple } \\
\text { Entidades no } \\
\text { bancarias }\end{array}$ & 1,191 & 1,470 & 1,510 & 1,829 & 1,952 & 2,481 \\
$\quad$ Total & 474 & 551 & 585 & 618 & 702 & 490 \\
\hline
\end{tabular}

Fuente: BCRP, estadísticas económicas (2015). 
En la tabla 1 se puede apreciar que el crédito otorgado por las entidades financieras en la región Áncash, en el año 2010, fue de 1 mil 749 millones de soles, luego de trascurrido los siguientes cinco años (2015), llegó hasta 3 mil 184 millones de nuevos soles, mostrando un crecimiento de $82 \%$, hecho contradictorio con lo que sucede con el PBI regional.

Existe una brecha entre las empresas y familias que reciben crédito. En la región Áncash, son las empresas con mayor monto de crédito, lo cual tiene sentido ya que las empresas destinan mayores recursos financieros para la compra de maquinarias, equipos, insumos y otros, mientras que las familias los destinan básicamente para compra bienes de consumo final.

Tabla 2: Créditos otorgados en Áncash (saldo en millones de soles)

\begin{tabular}{ccccccc}
\hline \multirow{2}{*}{ Tipo de créditos } & & \multicolumn{5}{c}{ Años } \\
\cline { 3 - 6 } & 2010 & 2011 & 2012 & 2013 & 2014 & 2015 \\
\hline Crédito a & 1047 & 1316 & 1,275 & 1,525 & 1,745 & 1,952 \\
empresas & 702 & 793 & 916 & 1,080 & 1,091 & 1,232 \\
Crédito a familias & 568 & 633 & 731 & 854 & 823 & 933 \\
Consumo & 134 & 160 & 185 & 226 & 268 & 300 \\
Hipotecario & 134,749 & 2,109 & 2,1910 & 2,605 & 2,836 & 3,184 \\
TOTAL & 1,709 &
\end{tabular}

Fuente: BCRP, sucursal Trujillo, estadísticas económicas (2015)

En la tabla 2, se muestra el crecimiento sostenido del crédito bancario en la región Ancash. Esta información nos revela que la colocación de crédito bancario va en sentido contrario que la economía regional, lo cual ya es una señal de riego crediticio.

Para evidenciar lo expresado, analicemos el indicador de esta variable, que viene a ser la tasa de morosidad del sistema financiero. Cuando la cartera pesada del sistema financiero sube, es porque los prestatarios han dejado de pagar a los prestamistas, produciéndose morosidad. Entre los años 2010 - 2015, años, la morosidad más alta se halla en las entidades no bancarias conocidas como micro financieras en la región Áncash, hecho que está relacionado con los créditos que otorgan estas entidades a la micro y pequeñas empresas, que son muy vulnerables a los cambios económicos, por esta razón los riesgos crediticios (morosidad) se eleva mayormente en este segmento empresarial.

En la siguiente tabla 3, se muestra la correlación entre las variables desaceleración de la economía regional, y el riesgo crediticio expresada en tasa de morosi- 
dad. Cuando la economía regional tiende a caer, a partir de 2010, la tasa de morosidad tanto de la banca múltiple como de las entidades no bancarias, tienden a crecer, de ese modo se produce una relación inversa entre estas dos variables.

Tabla 3: Evolución de la economía regional y tasa de morosidad crediticia (var.\%)

\begin{tabular}{ccccccc}
\hline Variables & \multicolumn{5}{c}{ Años } \\
\cline { 2 - 6 } & 2010 & 2011 & 2012 & 2013 & 2014 & 2015 \\
\hline $\begin{array}{c}\text { Desaceleración del PBI } \\
\text { regional }\end{array}$ & $18.2 \%$ & $14.7 \%$ & $3 \%$ & $3.2 \%$ & $-9.9 \%$ & $2.1 \%$ \\
$\begin{array}{c}\text { Tasa de morosidad de banca } \\
\text { múltiple }\end{array}$ & $2.1 \%$ & $2.2 \%$ & $2.7 \%$ & $3.4 \%$ & $4.6 \%$ & $5.8 \%$ \\
$\begin{array}{c}\text { Tasa de morosidad de } \\
\text { entidades no bancarias }\end{array}$ & $7 \%$ & $6.3 \%$ & $8.3 \%$ & $11.2 \%$ & $7.6 \%$ & $10.2 \%$ \\
\hline
\end{tabular}

Fuente: BCRP, sucursal Trujillo, estadísticas 2015

En la tabla anterior, se muestra que el nivel de tasa de morosidad de las entidades no bancarias (microfinancieras), es mayor que la tasa de morosidad de la banca múltiple, en ambos casos dicha tasa es ascendente. En junio de 2010 presentaba un promedio de $2 \%$ de morosidad; luego, en setiembre de 2015 , la tasa de morosidad se ubica en $4.5 \%$, es decir, en menos de cinco años ha subido en $2.5 \%$.

Para confirmar la relación inversa entre la desaceleración de la economía regional y el riesgo crediticio expresado en la tasa de morosidad, se aplicó la prueba de correlación a través del coeficiente de Pearson, obteniendo - 0.833 grados de asociación entre las variables mencionadas, para un nivel de confianza de 95\%, al resultar 0.040 de significancia bilateral.

Tabla. 3. Resultado de correlación de Pearson

\begin{tabular}{cc}
\hline Correlación de Pearson & Tasa de morosidad crediticia. \\
\hline Crecimiento del PBI regional & $-0,832^{*}$ \\
Sig. (bilateral) & 0,040 \\
La correlación es significante \\
al nivel 0,05 (bilateral).
\end{tabular}




\section{DISCUSIÓN}

Siguiendo a Keynes (1943), Mankiw (2006) y Blanchard (2012), en épocas de bonanza económica los agentes se entusiasman y elevan su demanda, hecho que ha ocurrido en la región Áncash, entre los años 2010-2015. La evidencia está en que la banca múltiple y las entidades no bancarias (micro financieras), han venido colocando mayores créditos a las empresas y familias; algunos han destinado para compras y otros para pago de deudas, esto ha venido ocurriendo en plena desaceleración de la economía regional. Hecho que suele ocurrir en el corto plazo por la percepción positiva de las empresas y familias sobre el futuro de la economía y se endeudan con cargo a sus ingresos futuros.

Es así que frente a la tendencia decreciente del PBI regional, los agentes económicos de inmediato no ajustaron sus gatos, por el contrario, mantuvieron expectativas optimistas de mayores ingresos en el corto plazo - lo cual es absolutamente incierto, porque la gran parte de la economía regional depende la demanda internacional de materias primas (minería)- al no ajustarse el nivel de consumo las familias terminaron endeudándose, en ese momento es cuando se incuba un mayor riesgo crediticio, para luego expresarse en una creciente tasa de morosidad.

El segmento micro y pequeñas empresas (MYPEs), son los que mayormente carecen de capital de trabajo, por lo que generalmente recurren a créditos bancarios. Estas empresas son altamente vulnerables frente shocks económicos, debido a que enfrentan un alto costo fijo respecto a las empresas modernas de mayor dimensión, lo que les impide reducir costos y precios unitarios, siendo esta una desventaja al momento de competir en el mercado en un contexto donde la demanda agregada tiende a contraerse. En la región Áncash, la reducción de las ventas de MYPEs está asociada directamente con la desaceleración de la economía regional, lo cual a su vez está relacionada con la creciente tasa de morosidad de entidades no bancarias, al ser estas las principales entidades que otorgan créditos a este segmento empresas.

De otro lado, la mayoría de las familias han mantenido un nivel de consumo permanente, entre los años 2010-2015, al no ajustar su nivel de consumo ante la desaceleración de la economía, se produjo déficits en el presupuesto de las familias, que han sido cubiertas mediante créditos, con la expectativas del retorno de boom económico en el corto plazo.

Como sostienen Vera (2007), Minzer (2011) y Meneses (2013) por el elevado optimismo sobre la pronta recuperación de la economía, se produce un alto apalancamiento empresarial y familiar. En la región Áncash, ante la sobrevaloración de los colaterales como el precio de los terrenos y viviendas, las compras han 
sido financiadas con créditos. Obviamente, cuando la deuda crece y no llegan los ingresos, el impacto va a ser negativo, para los prestamistas y prestatarios, elevándose de ese modo el riego crediticio.

\section{CONCLUSIONES}

Las empresas y familias en la región Áncash, entre los años 2010 y 2015, percibían con optimismo del futuro económico de la región, por lo que no ajustaron sus compras ante la desaceleración de la economía regional, sino, que financiaron los déficits con mayor endeudamiento vía crédito bancario.

En la economía de la región Áncash se ha detectado que existe una correlación negativa entre las variables desaceleración del PBI regional y la tasa de morosidad crediticia que representa el riesgo crediticio. El grado de correlación entre las variables es -0.83 , estimado por el coeficiente de Pearson, con un nivel de confianza de $95 \%$.

\section{REFERENCIAS BIBLIOGRÁFICAS}

Blanchard, Olivier; Amighini Alessia y Giavazzi Francesco. 2012. Macroeconomía (5ta ed). Madrid, Pearson Educación S.A.

Banco Central de Reserva del Perú. 2015. Estadísticas Económicas. Recuperado de <http://www.bcrp.gob.pe/estadisticas/informacion-regional/trujillo/ancash.html $>$ [25-12-16].

Banco Central de Reserva del Perú. 2016. Estadísticas Económicas. Recuperado de <http://www.bcrp.gob.pe/estadisticas.html $>$ [24-7-16].

Delgado, Javier y Saurina, Jesús (2004). Riesgo de crédito y dotaciones a insolvencias. Un análisis con variables macroeconómicas, Moneda y Crédito, $\mathrm{N}^{\circ}$ 219. 11-41.

Keynes, J. 1943. Teoría general de la ocupación, el interés y el dinero. Primera Edición en Español. México. Fondo de Cultura Económica. Primera edición en ingles 1936.

Mankiw, Gregory. 2006. Macroeconomía. Sexta edición. España, Antoni Bosch Editores

Meneses, Angel y Macuacé, Ronald. 2013. Valoración de riesgo crediticio en Colombia. Revistas Finanzas y Política Económica. Vol. 3. N² 2. Bogotá: 65-81.

Minzer, Rodolfo. 2011. Las Instituciones Micro financieras en América Latina: Factores que explican su Desempeño. México: Sede Subregional de la CEPAL 
|Antonio Huamán Osorio

Vera, Leonardo y Costa, Irene. 2007. Estimación y Proyección de la Calidad de la Cartera de Crédito utilizando variables Macroeconómicas. Un estudio para Venezuela. Revista de Economía y Estadística. Vol. 45. № 2. Córdoba.

Presentado: $31 / 01 / 2017$

Aceptado: 01/05/2017

\section{Correspondencia}

Antonio Huamán Osorio

antonio_ho10@yahoo.es 